Corrigendum

\title{
Corrigendum to "Biochemical and Biological Profile of Parotoid Secretion of the Amazonian Rhinella marina (Anura: Bufonidae)"
}

\author{
Daniel S. S. de Medeiros $\left(\mathbb{D},{ }^{1,2,3}\right.$ Tiago B. Rego ${ }^{D},{ }^{1}$ Ana P. de A. dos Santos, ${ }^{1,2,3}$ \\ Adriana S. Pontes, ${ }^{4}$ Leandro S. Moreira-Dill (1), ${ }^{1,3}$ Najla B. Matos, ${ }^{3,5}$ \\ Juliana P. Zuliani, ${ }^{3,4}$ Rodrigo G. Stábeli, ${ }^{1,3}$ Carolina B. G. Teles, ${ }^{2,3}$ \\ Andreimar M. Soares, ${ }^{1,3}$ Angelo R. de M. Sperotto, ${ }^{6}$ Dinara J. Moura, ${ }^{6}$ \\ Jenifer Saffi, ${ }^{6}$ Cleópatra Alves da Silva Caldeira, ${ }^{1}$ \\ Daniel Carvalho Pimenta $\mathbb{D}^{7},{ }^{7}$ and Leonardo A. Calderon $\mathbb{D}^{1,3}$ \\ ${ }^{1}$ Centro de Estudos de Biomoléculas Aplicadas à Saúde (CEBio), Fiocruz-Rondônia and Universidade Federal de Rondônia, \\ Porto Velho, 76812-245, Brazil \\ ${ }^{2}$ Plataforma de Bioensaios de Malária e Leishmaniose (PBML), FIOCRUZ-Rondônia, Porto Velho, 76812-245, Brazil \\ ${ }^{3}$ Instituto Nacional de Epidemiologia na Amazônia Ocidental, Porto Velho, 76812-245, Brazil \\ ${ }^{4}$ Laboratório de Imunologia Aplicada à Saúde, FIOCRUZ-Rondônia, Porto Velho, 76812-245, Brazil \\ ${ }^{5}$ Laboratório de Microbiologia, FIOCRUZ-Rondônia, Porto Velho, 76812-245, Brazil \\ ${ }^{6}$ Laboratório de Genética Toxicológica, Universidade Federal de Ciências da Saúde de Porto Alegre, Porto Alegre, 90050-170, Brazil \\ ${ }^{7}$ Laboratório de Bioquímica e Biofísica, Instituto Butantan, Avenida Vital Brazil, 1500, 05503-900 Sao Paulo, SP, Brazil
}

Correspondence should be addressed to Leonardo A. Calderon; calderon@unir.br

Received 30 April 2019; Accepted 2 May 2019; Published 27 May 2019

Copyright (c) 2019 Daniel S. S. de Medeiros et al. This is an open access article distributed under the Creative Commons Attribution License, which permits unrestricted use, distribution, and reproduction in any medium, provided the original work is properly cited.

In the article titled "Biochemical and Biological Profile of Parotoid Secretion of the Amazonian Rhinella marina (Anura: Bufonidae)" [1], Drs. Cleópatra Alves da Silva Caldeira and Daniel Carvalho Pimenta, who were responsible for the mass spectrometry analysis, were missing from the authors' list. The corrected authors' list is shown above and updated in place.

\section{References}

[1] D. S. Medeiros, T. B. Rego, A. P. Santos et al., "Biochemical and biological profile of parotoid secretion of the Amazonian Rhinella marina (Anura: Bufonidae)," BioMed Research International, vol. 2019, Article ID 2492315, 15 pages, 2019. 


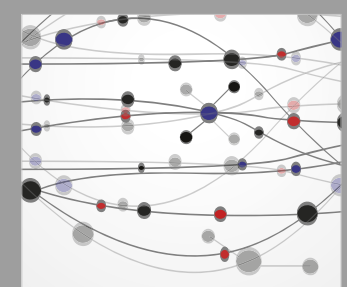

The Scientific World Journal
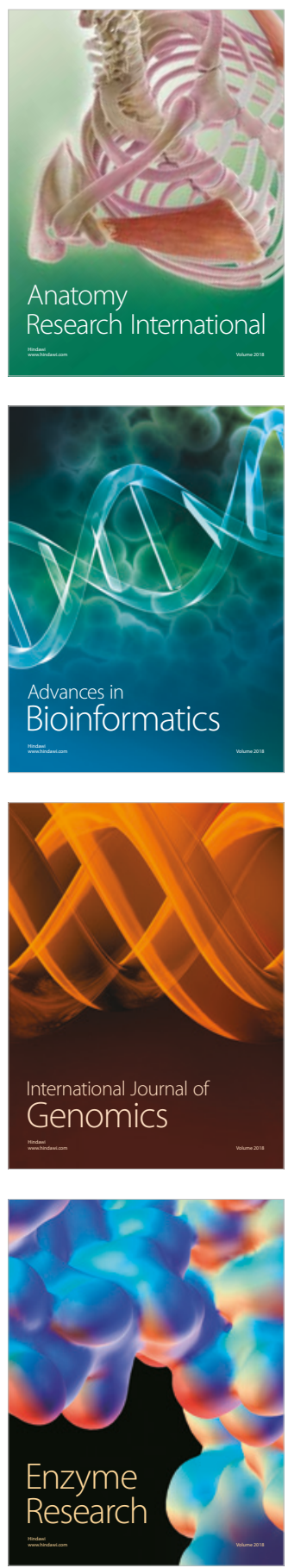
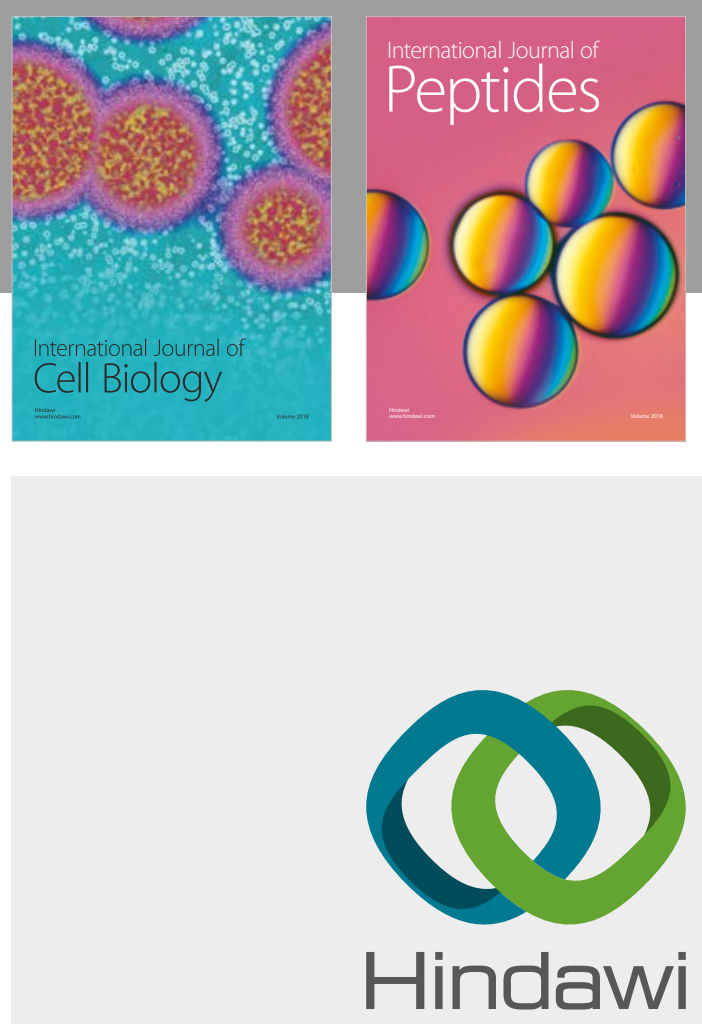

Submit your manuscripts at

www.hindawi.com
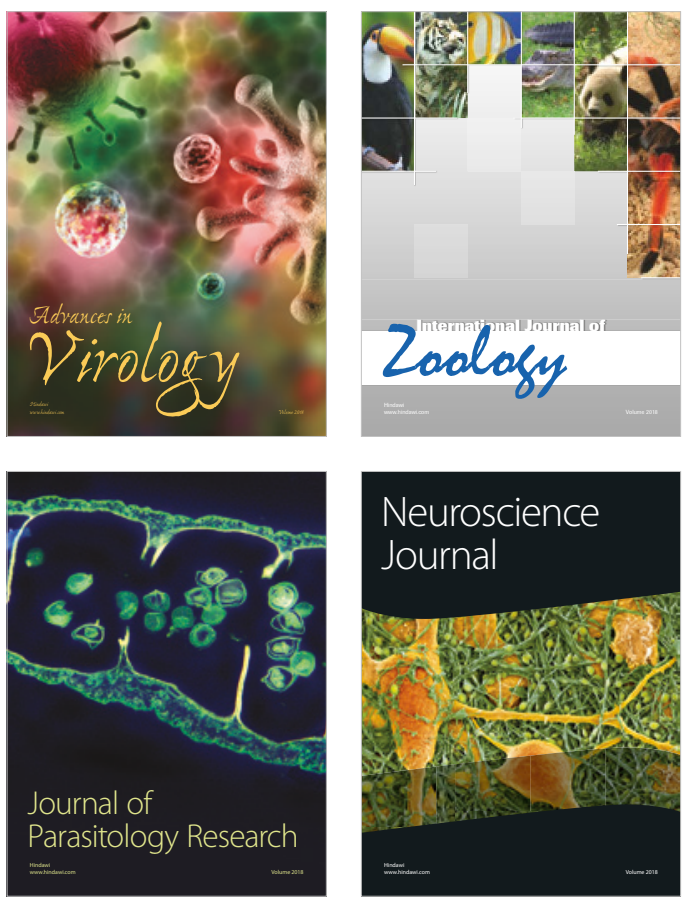
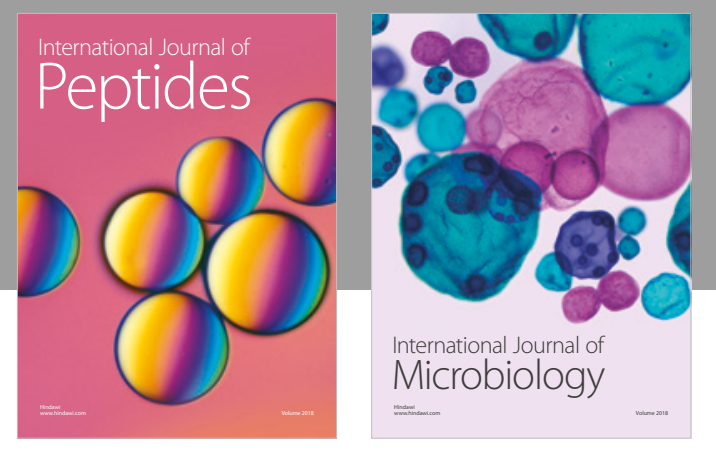

nternational Journal of Microbiology
Journal of
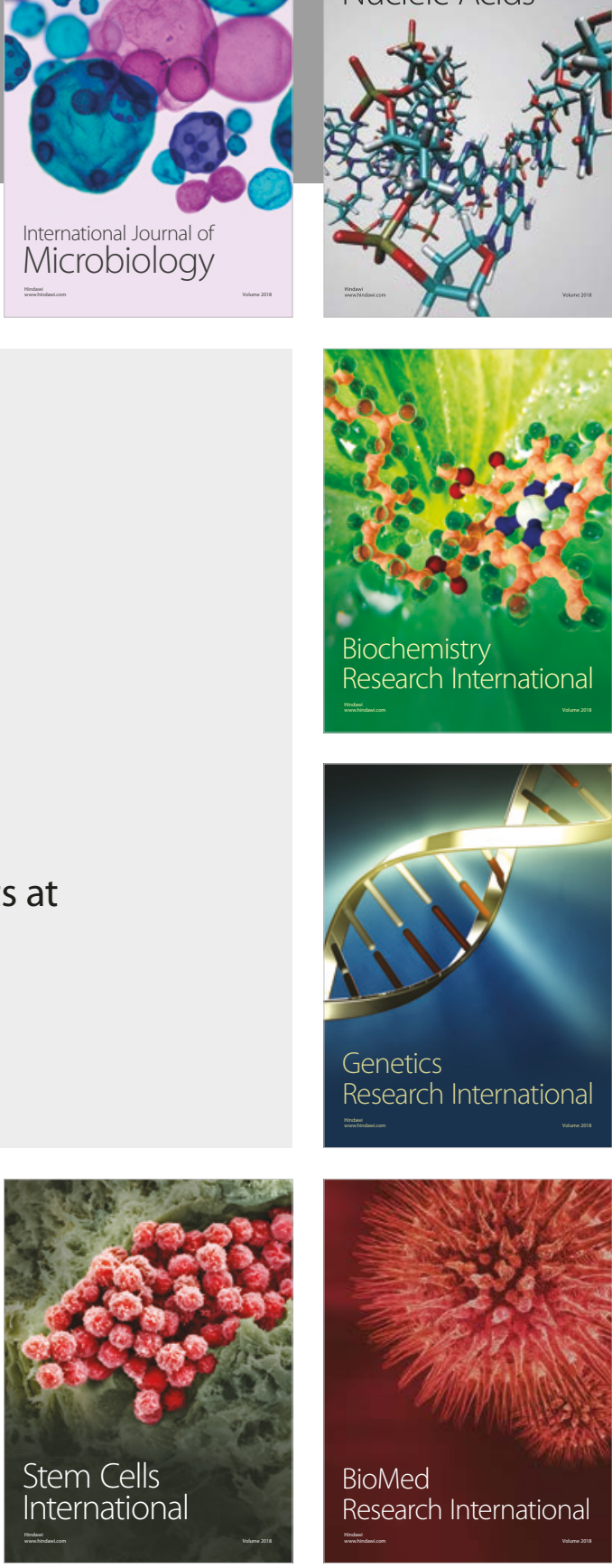
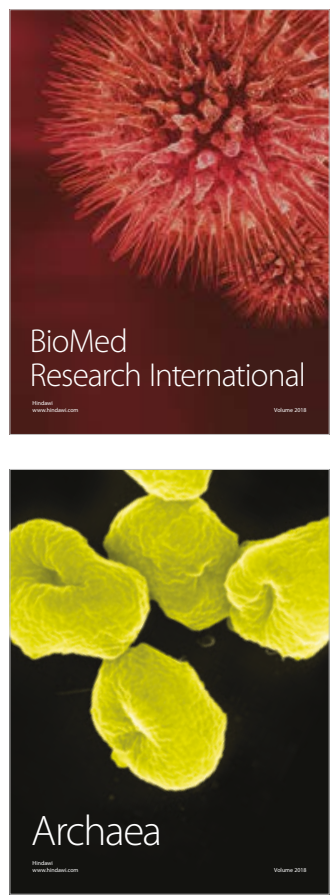